WHITE PAPER FOR THE

PLANETARY SCIENCE DECADAL SURVEY OF 2023-2032

\title{
Scientific Exploration of Venus with Aerial Platforms
}

\author{
Primary author: James A. Cutts \\ Jet Propulsion Laboratory, California Institute of Technology \\ Phone: (818)354-4120 \\ E-Mail: James.A.Cutts@jpl.nasa.gov
}

\section{Co-authors}

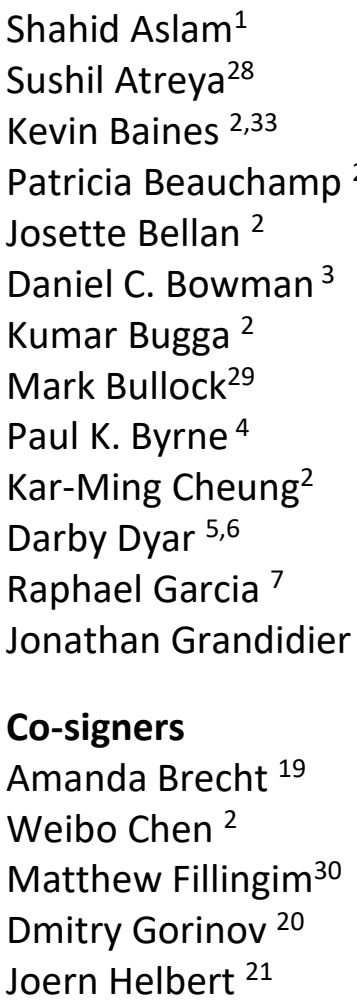

Shahid Aslam ${ }^{1}$

Sushil Atreya 28

Kevin Baines 2,33

Patricia Beauchamp ${ }^{2}$

Josette Bellan ${ }^{2}$

Daniel C. Bowman ${ }^{3}$

Kumar Bugga ${ }^{2}$

Mark Bullock ${ }^{29}$

Paul K. Byrne ${ }^{4}$

Kar-Ming Cheung ${ }^{2}$

Darby Dyar 5,6

Raphael Garcia 7

\section{Co-signers}

Amanda Brecht ${ }^{19}$

Weibo Chen ${ }^{2}$

Matthew Fillingim ${ }^{30}$

Joern Helbert ${ }^{21}$

\section{Institutions}

1. NASA Goddard Space Flight Center

2. California Institute of Technology

3. Sandia National Laboratories

4. North Carolina State University

5. Planetary Science Institute

6. Mount Holyoke College

7. Institut Supérieur de l'Aéronautique et de l'Espace-

SUPAERO, Toulouse, France

8. South West Research Institute

9. Thin Red Line Aerospace

10. Centre National de la Recherche Scientifique (CNRS)

11. Arizona State University

12. University of Colorado, Boulder

13. Planetary Science Institute

14. Aix-Marseille Universite

15. Global Aerospace Corporation

16. University of California, Los Angeles

Robert Grimm $^{8}$
David Grinspoon $^{5}$
Maxim De Jong, ${ }^{9}$
Jeffery Hall ${ }^{2}$
Jacob Izraelevitz $^{2}$
Jennifer M. Jackson $^{2}$
Kandis Lea Jessup $^{8}$
Attila Komjathy $^{2}$
Siddharth Krishnamoorthy $^{2}$
Sebastien Lebonnois
${ }^{7}$
Kevin McGouldrick
${ }^{12}$
David Mimoun ${ }^{7}$
Olivier Mousis ${ }^{14}$

Noam Izenberg 22

Anastasia Kosenkova 23

Tibor Kremic ${ }^{24}$

Ye Lu ${ }^{25}$

Alexey Martynov 23

\author{
Kerry Nock ${ }^{15}$ \\ Joseph O'Rourke ${ }^{11}$ \\ Michael T. Pauken ${ }^{2}$ \\ Jason Rabinovitch ${ }^{2}$ \\ Jean-Baptiste Renard ${ }^{10}$ \\ Gerald Schubert ${ }^{16}$ \\ David Senske ${ }^{2}$ \\ Christophe Sotin ${ }^{2}$ \\ Thomas W. Thompson ${ }^{2}$ \\ Nicolas Verdier ${ }^{17}$ \\ Panagiotis Vergados ${ }^{2}$ \\ Colin Wilson ${ }^{18}$ \\ Eliot F. Young ${ }^{8}$
}

Ryan McCabe ${ }^{26}$
Patrick McGovern ${ }^{27}$
Sara Seager ${ }^{31}$
Constantine Tsang ${ }^{8}$
Michael Way ${ }^{32}$ 
INTRODUCTION: After a long hiatus in Venus exploration by NASA, new exploration approaches have emerged that will help answer fundamental hypotheses about the planet. Aerial platforms ("aerobots") operating within the Venus cloud layer can address questions about the physical, chemical and astrobiological nature of the atmosphere and also be used to apply geophysical techniques to the investigation of the interior of the planet. In addition, infrared imaging from below the cloud layer can characterize the lithology and oxidations state of rocks at high spatial resolution. The technologies for highly capable aerobots can be ready to support new missions in the coming decade 2023-2032.

THE VEGA BALLOON MISSIONS: The first deep-space mission to demonstrate extended duration flight in the atmosphere of another planet was the Soviet VeGa mission to Venus in 1985 [1]. Two 3.5-m-diameter balloons were deployed from the VeGa landers during their descent to the surface of Venus. Each balloon floated at an altitude of $54 \mathrm{~km}$ and operated for about 48 hours before their batteries were exhausted. These missions, with their limited payloads $(7 \mathrm{~kg}$ total suspended mass including batteries), demonstrated the feasibility of balloon flight at Venus. Tracking of the balloons from Earth as they each traveled a third of the way around the planet also provided the first truly definitive measurements of the retrograde super-rotating zonal (RSZ) circulation and revealed evidence of gravity waves associated with major topographic features of the planet. VeGa balloons also recorded temperature, pressure, vertical wind speed, ambient light levels and cloud backscatter demonstrating the utility of in situ measurements in the Venus cloud layer [2]. Now, 35 years later and looking forward to the decade 2023 - 2032, we have a much richer set of scientific questions to ask about Venus, more sophisticated instruments with which to address these questions and aerobots with much larger scientific payload, altitude control capabilities and a greatly extended lifetime.

SCIENTIFIC OPPORTUNITIES WITH AEROBOTS: The scientific capabilities of aerobots are no longer limited to atmospheric dynamics although these investigations can be much more capable than VeGA and in concert with orbital measurements can comprehensively address the questions of what causes and sustains the RSZ circulation. Aerobot capabilities include investigations of the gas and aerosol chemistry of the cloud layer and its potential habitability. They extend to a range of geophysical investigations of the planet including remanent magnetism, electromagnetics sounding and infrasound seismology. Higher temperature aerobots that can reach the cloud layer base should be able to acquire infrared imaging of the surface for characterizing surface lithology that is higher in spatial resolution than is possible from orbit. Finally, aerobots can serve as a platform for deploying sondes capable of rising to the top of clouds, probing well below the cloud layer and imaging the surface in visible light. The types of instruments (Table 1) enabling these aerobot and sonde investigations are now considered.

Atmospheric Structure, Dynamics, and Infrasound (ASDI): This experiment would be capable of making meteorological and geophysical measurements. In addition to measuring temperature, pressure and platform-relative wind velocity, it would have the capability of detecting gravity waves and infrasound generated by quakes and volcanic eruptions [3]. The InSight Missions's Auxiliary Payload Suite (APSS) includes most of the key sensor capabilities needed for this experiment when adapted to operate under the environmental condition at Venus [4] 
Radioscience: Tracking of the VeGa balloons from Earth provided in situ measurements of zonal wind velocity in the cloud layer. Range-Doppler tracking of an aerobot from both the Earth and an orbiter would not be limited to the Earth-facing hemisphere of Venus, and allow localization to better than $100 \mathrm{~m}$ [5], measurement of zonal, meridional and vertical wind components; and characterization of temperature structure of the atmosphere above the aerobot.

Nephelometer (Neph): Cloud and aerosol particle number, size, and scattering properties can be determined by measuring optical scattering properties. Instruments capable of resolving individual aerosol particles include the Light Optical Nephelometer Sizer and Counter for Aerosols for Planetary Environments (LONSCAPE) [6] and the Planetary Polarization Nephelometer [7].

Net Flux Radiometer (NFR): Measurements of the net flux of visible and infrared radiation are necessary for understanding the absorption of radiation in the cloud layer and its effect on atmospheric circulation. An advanced net flux radiometer developed for the outer planets [8] can be adapted for a 100-Earth-day mission in the Venus clouds

Aerosol and Gas Mass Spectrometer (AGMS): Measurements of noble gases and their isotopes, as well as profiles of active species such as $\mathrm{SO}_{2}, \mathrm{OCS}, \mathrm{H}_{2} \mathrm{O} \& \mathrm{HCl}$, as a function of altitude, latitude, and time of day would be made by this experiment. A separator that isolates cloud droplets and aerosol particles from the ambient gas is needed to independently measure composition of both cloud and aerosol particles and of the gas, which surrounds them [9]. Such measurements would address hypotheses about the chemical nature of the clouds [10] as well as recent conjectures about the potential habitability of the Venus cloud layer [11].

Table 1. Key experiments and measurement types for aerobot atmospheric, geophysical, and geological investigations. These measurements address the Goals, Objectives and Investigations (GOI) in VEXAG's Venus Strategic Plan. An exploration of the GOI codes targeted appears in Table 2.

\begin{tabular}{|l|c|l|l|}
\hline \multicolumn{1}{|c|}{ Experiments } & Abbr. & \multicolumn{1}{|c|}{ Measurement Type/Objectives } & \multicolumn{1}{|c|}{ GOI Codes Targeted } \\
\hline $\begin{array}{l}\text { Atmospheric Structure Dynamics } \\
\text { and Infrasound }\end{array}$ & ASDI & $\begin{array}{l}\text { Temperature, pressure, vertical wind speed, gravity waves } \\
\text { and infrasound }\end{array}$ & $\begin{array}{l}\text { I.A.RI, I.B.LI,I.B.CO, II.A.DD, II.A.MP, } \\
\text { III.A.GA, III.A.CR }\end{array}$ \\
\hline \hline RadioScience & RS & $\begin{array}{l}\text { Wind velocity and location from Range. Doppler signatures } \\
\text { from DSN Earth station and and Venus orbiter }\end{array}$ & II.A.DD, II.A.MP, III.A.CR \\
\hline \hline Nephelometer & NFR & $\begin{array}{l}\text { Number, size and scattering properties of cloud aerosols. } \\
\text { Could be integrated with AGMS }\end{array}$ & $\begin{array}{l}\text { UlI.B.AE, II.B.UA } \\
\text { spectral bands }\end{array}$ \\
\hline \hline Net Flux Radiometer & AGMS & $\begin{array}{l}\text { Composition of noble gases and chemically active gases; } \\
\text { composition of aerosol particles }\end{array}$ & I.B.IS, I.B.IN, II.B.AE, II.B.UA \\
\hline \hline $\begin{array}{l}\text { Aerosol and Gas Mass } \\
\text { Spectrometer }\end{array}$ & MEM & $\begin{array}{l}\text { Remanant magnetic fields indicative of early Venus } \\
\text { dynamo. Crustal thickness and composition. }\end{array}$ & I.A.MA, I.B.LI, IIII.A.CR \\
\hline $\begin{array}{l}\text { Magnetism and } \\
\text { Elecromagnetism }\end{array}$ & ISSI & $\begin{array}{l}\text { High spatial resolution (<5m) maps of rock type and } \\
\text { oxidation state from emitted infrared radiation }\end{array}$ & I.A.HO, I.A.RE, II.B.OG, II.A.GH, \\
\hline \hline III.A.GC, III,A.GA, III.A.CR, III.B.LW, \\
\hline \hline Descent probe and/or sondes & DP\&S & $\begin{array}{l}\text { Profiles atmosphere either above or below the aerobot. } \\
\text { Acquire surface images in visible-range reflected light }\end{array}$ & ISSI Codes and II.A.DD, II.A.MP, II.B.UA \\
\hline
\end{tabular}

Magnetism and Electromagnetism (MEM): The proximity of the aerobot to the surface of Venus enables geophysical measurements with much greater sensitivity and spatial resolution than is possible from an orbiting spacecraft. Detection of remanent magnetization at horizontal scales similar to the $\sim 50-\mathrm{km}$ aerobot altitude, would test hypotheses of a permanent magnetic field existing early in Venus' history [12]. Measurements of changes in the magnetosphere induced by 
the solar wind enable probing of the planetary core [13]. Aerial electromagnetic sounding [14] can characterize regional variations in lithospheric thickness. The detection of lightning via electromagnetic and infrasound signatures enables determination of its occurrence rate, and assessment of its effect on atmospheric chemistry [15].

Infrared Surface Spectral Imager (ISIS): A global map of surface emissivity in the 1-1.5 $\mu \mathrm{m}$ spectral range [16] is a primary goal for orbital missions investigating the surface [17]. However, scattering in the cloud layer limits the spatial resolution to $50 \mathrm{~km}$, so that only very large surface features can be resolved. Observations from an aerial platform operating below the cloud layer [18] would enable spatial resolution substantially higher than possible from orbit.

Descent Probe and Sondes: Previous aerobot mission concepts have featured probes released after entry but prior to inflation of the balloon envelope [23] and sondes released after the aerobot has become operational [19]. Probes or sondes weighing a few kilograms can reach the surface [20] and ram-inflated solar balloons [21] with very small payloads (up-sondes) can ascend above the cloud tops. These deployments also serve as ballast extending aerobot lifetime. Data is relayed through the aerobot to reduce power requirements and enhance total data returns.

ASSESSMENT OF SCIENCE VALUE: The VEXAG Venus Strategic Plan 2019 [15]considered the science value of aerobots operating within the Venus cloud layer and equipped with the types of instruments described above. VEXAG (Venus Exploration Analysis Group) considered three aerobot types: A) Mid-Cloud Fixed-Altitude B) Mid-Cloud Variable-Altitude and C) Sub-Cloud Variable-altitude and evaluated the contribution of each type to addressing the VEXAG Goals, Objectives and Investigations (GOI). The result of that assessment appears in Table 2,

Table 2 Contributions of measurements made the three Venus aerobot types to addressing the Goals, objectives and Investigations established by VEXAG [15]

\begin{tabular}{|c|c|c|c|c|c|c|c|}
\hline \multicolumn{5}{|c|}{ VEXAG Goals, Objectives and Investigations } & \multicolumn{3}{|c|}{ Aerobot Type } \\
\hline Goals & Objectives & Investigations & $\begin{array}{l}\text { GOI } \\
\text { Code }\end{array}$ & $\begin{array}{c}\text { GOI } \\
\text { Rating }\end{array}$ & $\begin{array}{l}\text { Fixed Altitude } \\
\text { Mid Cloud (A) }\end{array}$ & $\begin{array}{l}\text { Variable Altitude } \\
\text { Mid Cloud (B) }\end{array}$ & $\begin{array}{l}\text { Variable Altitude } \\
\text { Sub Cloud (C) }\end{array}$ \\
\hline \multirow{8}{*}{ 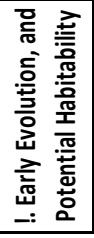 } & \multirow{4}{*}{$\begin{array}{l}\text { A. Did Venus have } \\
\text { liquid water? }\end{array}$} & Hydrous origins & I.A.HO & 1 & & & \\
\hline & & Recycling & I.A.RE & 1 & & & \\
\hline & & Atmospheric Losses & I.A.AL & 2 & & & \\
\hline & & Magnetism & I.A.MA & 3 & & & \\
\hline & \multirow{4}{*}{$\begin{array}{l}\text { B. How does } \\
\text { Venus elucidate } \\
\text { pathways for } \\
\text { planet evolution }\end{array}$} & Isotopes & I.B.IS & 1 & & & \\
\hline & & Lithosphere & I.B.LI & 1 & & & \\
\hline & & Heat flow & I.B.HF & 2 & & & \\
\hline & & Core & I.B.CO & 2 & & & \\
\hline \multirow{8}{*}{ 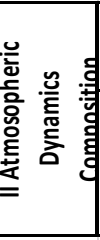 } & \multirow{3}{*}{$\begin{array}{l}\text { A. What drives } \\
\text { global dynamics }\end{array}$} & Deep Dynamics & II.A.DD & 1 & & & \\
\hline & & Upper Dynamics & II.A.UD & 1 & & & \\
\hline & & Mesoscale Processes & II.A.MP & 2 & & & \\
\hline & \multirow{5}{*}{$\begin{array}{l}\text { B. What governs } \\
\text { compositions and } \\
\text { radiative balance? }\end{array}$} & Radiative Balance & II.B.RB & 1 & & & \\
\hline & & Interactions & II.B.IN & 1 & & & \\
\hline & & Aerosols & II.B.AE & 2 & & & \\
\hline & & Unknown UV absorber & II.B.UA & 2 & & & \\
\hline & & Outgassing & II.B.OG & 3 & & & \\
\hline \multirow{7}{*}{ 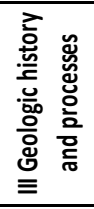 } & \multirow{4}{*}{$\begin{array}{l}\text { A. What geological } \\
\text { processes shape } \\
\text { the surface }\end{array}$} & Geologic history & III.A.GH & 1 & & & \\
\hline & & Geochemistry & III.A.GC & 1 & & & \\
\hline & & Geologic Activity & III.A.GA & 2 & & & \\
\hline & & Crustal & III.A.CR & 2 & & & \\
\hline & \multirow{3}{*}{$\begin{array}{l}\text { B. How do the } \\
\text { atmosphere and } \\
\text { surface interact }\end{array}$} & \multirow{3}{*}{$\begin{array}{l}\text { Local Weathering } \\
\text { Global Weathering } \\
\text { Chemical Interactions }\end{array}$} & III.B.LW & 1 & & & \\
\hline & & & III.B.GW & 2 & & & \\
\hline & & & III.B.CI & 3 & & & \\
\hline & Enables measurem & ents that are vital alone & combinat & ion to & mpleting inve & gation & \\
\hline & Enables measurme & nts that substantially ac & the inve & stigatio & & & \\
\hline
\end{tabular}


All three types of aerobot can make significant scientific contributions to the Venus Goals Objectives and Investigations. Type B has substantial advantages over Type A, due to its ability to achieve vertical profiling within the cloud layer. Type $C$, which is capable of surface infrared imaging at high spatial resolution, can make a major contribution to VEXAG's Goal III- Geologic History and Processes through investigations of geochemistry (III.A.GC), global weathering (III.B.GW), and chemical interactions (III.B.CI).

AEROBOT DESIGN CONSIDERATIONS: The three type of aerobot described above and in Table 1 emerged from a NASA-sponsored study - Aerial Platforms for the Scientific Exploration of Venus [18] that had the goal of assessing the unique science feasible with aerial platforms, and defining the optimal technical approach. The options studied included vehicles relying exclusively on buoyancy, vehicles using aerodynamic lift, and hybrid concepts using a combination of the two. The study team assessed the scientific capabilities of each concept, the maturity of the technology, and the size and complexity of the systems needed for implementation. The study concluded that buoyant vehicle (aerobots) were significantly more effective in addressing the VEXAG-defined scientific goals for Venus than either solar airplanes or hybrid vehicles that employ a combination of buoyancy and aerodynamic lift. The current state of development of the three types of aerobot identified in Table 2 is now considered.

Type A- Fixed-Altitude, Mid-Cloud Aerobot: The technical concept is a superpressure balloon that maintains a constant buoyancy designed for float at a constant pressure altitude near $55 \mathrm{~km}$. In concept, these aerobots are larger versions of the VeGa balloons but they differ from VeGA in having to operate in the Venus daytime as well as nighttime. JPL has constructed prototype Venus balloons of this type (Figure 1a) capable of delivering an instrument module (gondola) with mass of 60 to $100 \mathrm{~kg}$ (Fig 1a) and a projected lifetime of 100 Earth days.

Type B-Variable-Altitude, Mid-Cloud Aerobot: This aerobot is capable of changing altitude over a range of $10 \mathrm{~km}$ in the middle of the cloud layer between 50 and $60 \mathrm{~km}$. The two most promising concepts for accomplishing this [22] are pumped compression, in which helium is pumped between a superpressure balloon and a zero-pressure balloon (Fig 1b), and mechanical compression in which buoyancy is modulated by a tether that changes the volume of a stack of interconnected superpressure balloon segments (Figs 1c and 1d). JPL and its partners are developing prototypes of both concepts. Altitude control involves mass and power penalties compared to the fixed-altitude aerobot (Type A) but a comparable operating lifetime.

Type C-Variable-Altitude, Sub-Cloud Aerobot: The ability to descend below the cloud layer and view the surface without degradation from scattering by cloud particles enables imaging of the surface in the near infrared at very much higher spatial resolution than from orbit. However, an aerobot descending below the cloud base to $46 \mathrm{~km}$ altitude would experience atmospheric temperatures in excess of $100^{\circ} \mathrm{C}$. This concept is a more technically challenging variant of the Type $B$ aerobot. It requires balloon envelope materials that tolerate these high temperatures in a sulfuric acid environment and thermal control approaches that enable science instrumentation capable of observations at higher temperatures than for Type B.

AEROBOT TECHNOLOGY DEVELOPMENT NEEDS: The technology for Type A aerobots has received significant investment [24] [25] and is most mature. Significant further work in needed on Type $B$ aerobots including completion and testing of subscale prototypes, followed by 
laboratory and flight tests of full-scale platforms. The Type C aerobots are more technically challenging and the focus should be on developing suitable materials and thermal control solutions. Rigid aeroshell technology for entry and descent at Venus needed for delivering aerobots to the planet is now mature [26], and ready to support a Venus aerobot mission.

None of the experiments described in this report requires new technology. However, further development work on packaging for environmental protection, miniaturization and integration to minimize overall payload mass and power is still required.

Computer models with sufficient fidelity to describe the flight of aerobots in the Venus environment are needed to support the design, development, and, ultimately, the operation of aerobots at Venus. A model currently under development at JPL uses the Dynamic and Real Time Simulation (DARTS) environment and leverages modeling capabilities for other in situ planetary exploration systems such as the Mars Curiosity landing system.

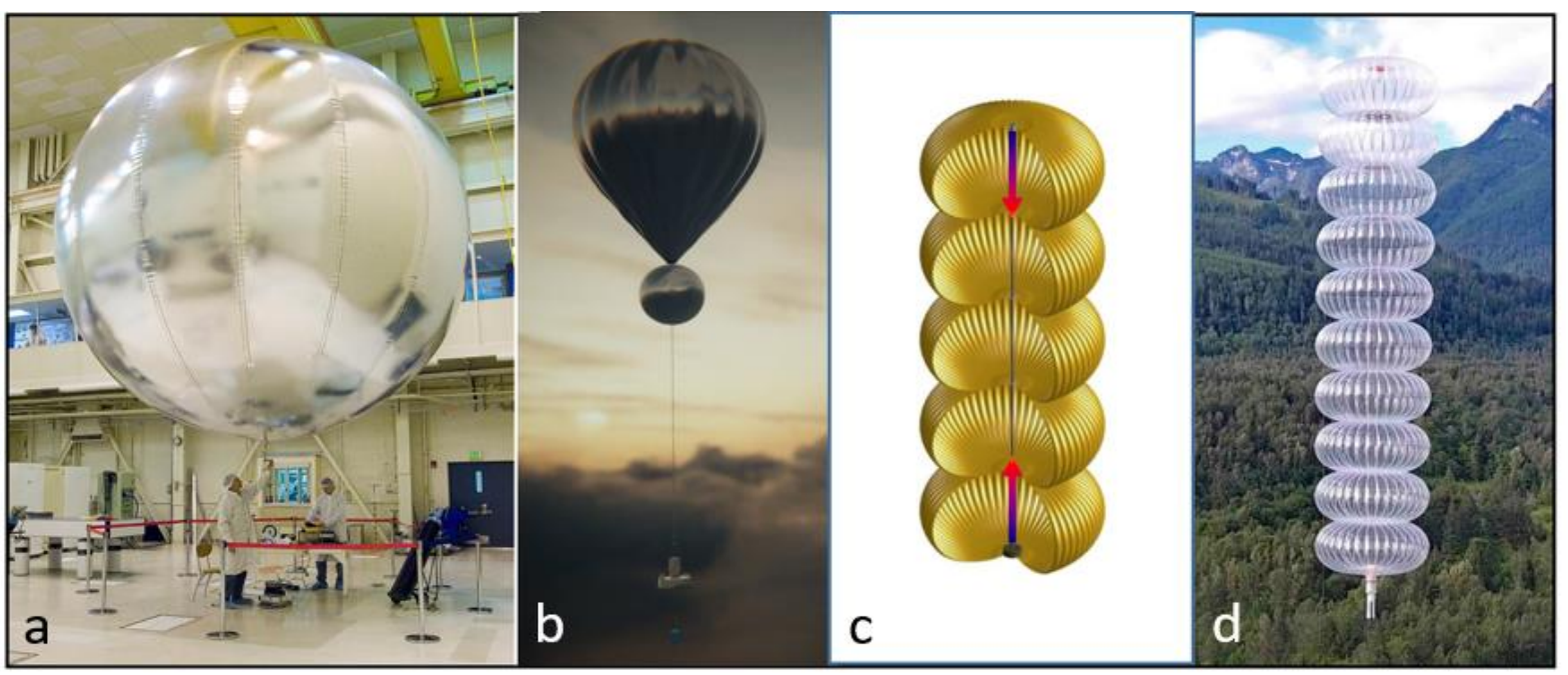

Figure 1: Design approaches for aerobots for exploring the Venus cloud layer. a) Type A (Superpressure, fixed-altitude) aerobot developed at JPL. An aluminized Teflon coating protects the balloon envelope from sulfuric acid and day-night cycles. b) The pumped compressions approach for a Type B or Caerobot. The lower balloon is a superpressure balloon as in a); helium is released into the upper balloon to cause it to rise and is pumped back out to cause it to descend. c) The mechanical compressions approach for a Type B or C aerobot. Buoyancy of the vehicle is increased by increasing the length of the tether connecting the pole pieces. d) A flight test prototype of mechanical compression aerobot (courtesy Thin Red Line Aerospace)

MISSION OPPORTUNITIES: There are flight opportunities for aerobot missions in NASA's Flagship, New Frontiers, Discovery and SIMPLEx programs.

Flagship Class Missions: In the last Planetary Decadal Survey, a Venus Climate Mission (VCM) was prioritized as a potential Flagship Mission [23]. VCM included an orbiter, a superpressure (constant altitude) balloon, a mini-probe, and two drop sondes. In 2019, the U.S.-Russia Venera D Joint Science Definition Team (JSDT) completed its report on a mission concept, in which Russia would furnish a lander and orbiter and NASA/U.S. would contribute other flight elements. A vertically maneuverable aerobot was identified as one of those elements [27]. Recently, in preparation for the Planetary Science Decadal Survey for 2023-2032, NASA initiated a Venus Flagship Mission (VFM) study under the Planetary Mission Concepts Studies (PMCS) program. The VFM concept [28] includes a variable-altitude aerobot. 
New Frontiers: VEXAG's Strategic Plan identifies the potential of "multi-platform mission" Venus missions-as New Frontiers candidates. Cost competitive concepts could not include the range of platforms that are included in the Venus Flagship Mission. However, a smaller complement of an aerobot equipped with the full range of instruments considered here and an orbiter providing telecom relay to earth, tracking and orbital remote sensing synergistic with the aerobot appears quite credible. Descent probes and/or sondes might also be feasible.

Discovery: Venus balloons have been proposed in previous Discovery mission competitions but not since 2010. The innovations in altitude control and science instrumentation described here would enable competitive Discovery proposals although the range of science addressed would be narrower than that possible with a New Frontiers budget.

SIMPLEx: The small size and the capability of the VeGA balloons reflects the scalability of the aerobot concept. Concepts proposed to the SIMPLEX program would have highly targeted science relative to other NASA programs [29].

SUMMARY: Aerobots operating in the Venus cloud layer can address major outstanding questions about the physical, chemical, and astrobiological nature of this region of the planet. Aerobots can also conduct geophysical investigations of the lithosphere and the planetary interior, and characterize the lithology and oxidations state of rocks at high spatial resolution. Aerobots build upon the successful Soviet flights in the 1980s, which used much less capable technologies than exist today. The technologies for aerobot platforms and their instruments can be matured to enable scientifically compelling missions in the decade 2023-2032.

\section{REFERENCES}

$$
\text { Pre-Decisional Information - For Planning and Discussion Purposes Only }
$$

[1] R. Z. Sagdeev, V. M. Linkin, J. E. Blamont and R. A. Preston, "The VEGA Venus Balloon Experiment," Science, pp. 1407-1408, 1986.

[2] R. Z. Sagdeev, "Overview of VEGA Venus In Situ Meteorological Measurements," Science, pp. 2311411, 1986.

[3] S. Krishnamoorthy, V. H. Lai, A. Komjathy, M. T. Pauken, J. A. Cutts, R. F. Garcia, D. Mimoun, J. M. Jackson, D. C. Bowman, E. Kassarian, L. Martier, A. Sournac and A. Cadu, "Aerial Seismology using Balloon-Based Barometers," IEEE Transaction on Geoscience and Remote Sensing. , 2019.

[4] D. Banfield, "InSight Auxiliary Payload Sensor Suite (APSS)," Space Sci. Rev., p. 215:4, 2019.

[5] K.-M. Cheung, W. Jun, C. Lee and G. Lightsey, "Single-Satellite Real-Time Positioning of Balloons for Aerial Exploration," in IAF Congress - Mobile Satcomm and Navigation, 2019.

[6] J.-B. Renard, O. Mousis, P. Rannou, A.-C. Levasseur-Regourd, G. Berthet, J.-M. Geffrin and N. Verdier, "Determining Physical Properites of Aerosols," Space Sci Rev, pp. 216-228, 2020.

[7] D. Banfield and R. Dissly, "Planetary Polarization Nephelometer," in International Workshop on Instrumentation for Planetary Missions, 2012.

[8] S. Aslam et al, "An Advanced Net Flux Radiometer for the Ice Giants," Space Science Rev., 216 (1):11 2020.

[9] K. Baines, D. Nikolic, J. Cutts, J.-B. Renard, S. M. Madzunkov, L. Barge, O. Mousis and S. Limaye, "An Aerosol-Sampling Instrument for Venus Cloud Habitability," Astrobiology, submitted, 2020. 
[10] F. P. Mills, L. Esposito and Y. Yung, "Atmospheric Composition Chemistry and Clouds," in Exploring Venus as A Terrestrial Planet Vol 176, AGU Geophysical Monograph Series, 2007.

[11] S. Limaye, K. Baines, M. Bullock, T. Milojevic, R. Mogul, L. Rothschild, S. Sasaki, D. SchultzeMakuch, D. Smith and M. Way, "Venus : An Astrobiology target," Astrobiology (submitted), 2020.

[12] J. G. O'Rourke, J. Buz, R. R. Fu and R. J. Lillis, "Detectability of Remenent Magnetism in the Curst of Venus," Geophysical Research Letters, 2019.

[13] C. Russell, M. Villarea, P. Chi, T. Zhang, J. Luhman and J. Ma, "Planetary Core Sounding with the Solar Wind Interaction: Application to Venus," in EPSC Abstracts, Vol. 9, id. EPSC2014-17, 2014.

[14] R. E. Grimm, A. C. Barr, K. P. Harrison, D. E. Stillman, K. L. Neal, M. A. Vincent and G. T. Delory, "Aerial Electromagnetic Sounding of the lithosphere of Venus," Icarus 217, pp. 462-473, 2012.

[15] D. Dyar and N. Izenberg, "Venus Strategic Documents," VEXAG, 2019.

[16] M. D. Dyar, J. Helbert, A. Maturilli, I. Varatharajan and T. Wideman, "Interpreting Venus Suaface Spectra from Orbit," in AGU Fall Meeting, 2019.

[17] J. Helbert, D. Wendler, I. Walter, T. Wideman and E. Marcq, "The Venus Emissivity Mapper Concept," in Optical Engineering and Applications, San Diego, 2016.

[18] J. Cutts, "Aerial Platforms for the Scientific Exploration of Venus,," JPL D-102569, 2018.

[19] K. Klaasen and R. Greeley, "VEVA Discovery Mission: Exploration of Volcanoes and Atmosphere," Acta Astronautica 53 (2-6), 2003.

[20] J. Izraelevitz and J. Hall, "Minimum Mass limits for streamlined Venus Atmospheric probes," AIAA Journal of Spacecraft and Rocket, 2020.

[21] J. Jones and M. Heun, "Montgolfiere balloon aerobots for planetary atmospheres.," in AIAA International Balloon Technology Conference AIAA 97-1445, 1997.

[22] J. Hall, J. M. Cameron, M. T. Pauken, J. S. izraelevitz, M. W. Dominquez and K. T. Wehage, "Venus Aerial Platform Technology Developments," in AIAA, 2019.

[23] S. Squyres, "Vision and Voyages for Planetary Science in the Decade 2023 to 2032," The National Academies Press; ISBN 978-0-309-22464-2, 2011.

[24] J. L. Hall, A. Yavrouian, V. V. Kerzhanovich, G. A. Plett, M. Said, D. Fairbrother, C. Sandy, G. Frederickson, G.Sharpe. and S. Day, Advances in Space Research, Vol 44 93-105, 2009.

[25] J. L. Hall, A. Yavrouian, V. V. Kerzhanovich, T. Frederickson, C. Sandy, M. Pauken, E. Kulczycki, G. J. Walsh, M. Said and S. Day, Advances in Space Research, 48(7):1238-1247, 2011.

[26] E. Venkatapathy, "Sustainability of Mature entry and TPS technologies for Enabling Future Venus missions," 2020. [Online].

[27] Venera D Joint Science Definition Team, "Venera D: Report of the Joint Science Definition Team Phase II Final Report," Roscosmos PS-02598, 2019.

[28] M. Gilmore, P. Beauchamp and S. Kane, "Venus Flagship Mission Study: Planetary Decadal Study: A Mission to the Closest Exoplanet," in Exoplanets in our Backyard, 2020.

[29] R. Grimm and M. Gilmore, "Venus Bridge Study," NASA Planetary Science Division, 2018.

Part of the research was carried out at the Jet Propulsion Laboratory, California Institute of Technology, under a contract with the National Aeronautics and Space Administration (80NM0018D0004).

Copyright 2020. All rights reserved. Government sponsorship is acknowledged. 